\title{
Malignant fibrous histiocytoma of the mediastinum
}

\author{
Praveen Aggarwal, Surender Kumar Sharma, A.B. Dey, Tushar Kanti \\ Chattopadhyay' and Meera Mathur ${ }^{2}$
}

\author{
Departments of Medicine, 'Surgery and ${ }^{2}$ Pathology, All India Institute of Medical Sciences, New Delhi 110029, \\ India.
}

\begin{abstract}
Summary: A case of malignant fibrous histiocytoma of the mediastinum presenting with unusual features of fever and leucocytosis is reported. This is the youngest patient reported in the literature who had this tumour in the mediastinum.
\end{abstract}

\section{Introduction}

Malignant fibrous histiocytoma is a neoplasm with fibroblastic and histiocytic differentiation that arises usually in the deep soft tissues. It has a predilection for the extremities, especially thighs. It occurs very rarely in the mediastinum. This paper reports a case of malignant fibrous histiocytoma of the posterior mediastinum occurring in a young girl who presented with fever.

\section{Case report}

A 16 year old girl presented to us with a 6-month history of fever, anorexia and weight loss. The fever was low grade and intermittent initially but became high grade and continuous for one month prior to coming to this hospital.

Physical examination showed an emaciated girl with moderate pallor and a temperature of $38.5^{\circ} \mathrm{C}$. The chest examination revealed findings suggestive of a mass lesion in the interscapular and infrascapular areas on the left side.

Investigations showed a haemoglobin of $4.5 \mathrm{~g} / \mathrm{dl}$, white blood cell count of $14.9 \times 10^{9} / 1(82 \%$ polymorphonuclear leucocytes), ESR was $60 \mathrm{~mm}$ in the 1st hour, serum iron was $78 \mu \mathrm{g} / \mathrm{dl}$ and total iron binding capacity $540 \mu \mathrm{g} / \mathrm{dl}$. The peripheral smear suggested an iron deficiency anaemia. The liver function tests were unremarkable. A bone marrow aspirate showed a hypercellular marrow, erythroid hyperplasia with normoblastic marrow. A chest X-ray revealed a large posterior mediastinal mass on the left side without any bony destruction or calcification (Figure 1). Computerized tomography of the chest disclosed a large soft tissue mass in the posterior mediastinum on the left side with a small area of calcification (Figure 2).

Correspondence: Surender K. Sharma, M.D.

Accepted: 14 March 1989.

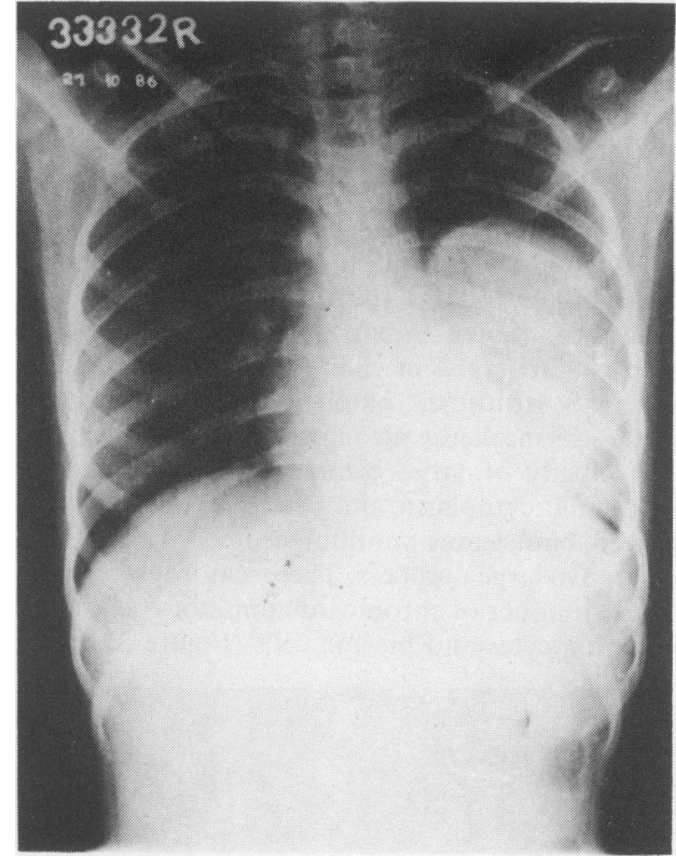

Figure 1 Anteroposterior chest radiograph showing a posterior mediastinal mass on the left side.

A percutaneous biopsy of the mass was done which on microscopy showed a mixture of small and large cells, the latter containing an abundant eosinophilic cytoplasm and a vesicular nucleus. These cells had a vague resemblance to ganglion cells. The biopsy was interpreted as ganglioneuroma.

With a pre-operative diagnosis of ganglioneuroma, the patient was operated. At thoracotomy, a large $15 \times 10 \mathrm{~cm}$ lobulated mass occupying the lower part of the posterior mediastinum and infiltrating the lower

(C) The Fellowship of Postgraduate Medicine, 1989 


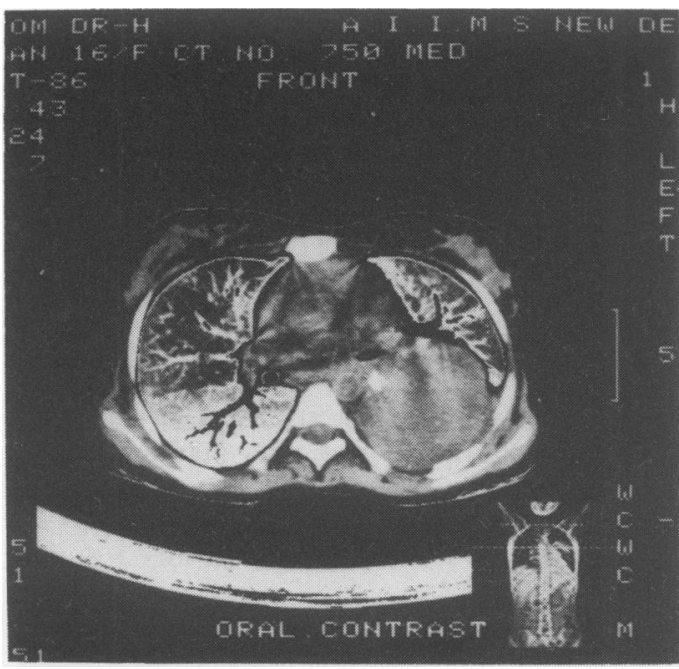

Figure 2 Computed tomography of the chest showing a soft tissue mass with an area of calcification in the posterior mediastinum.

lobe of the left lung was found. The tumour was excised along with the left lower lobe of the lung. The histopathology of this specimen revealed a variable appearance. Some areas showed spindle-shaped fibroblasts arranged in short fascicles and at places showing a stratiform pattern. In other areas, the tumour was markedly pleomorphic and cellular, composed chiefly of large bizarre cells with abundant eosinophilic cytoplasm and vesicular nucleus. Some cells were binucleate or multinucleated. Mitotic figures were seen in large numbers. There was infiltration by a variable number of chronic inflammatory cells chiefly the lymphocytes and plasma cells (Figure 3).

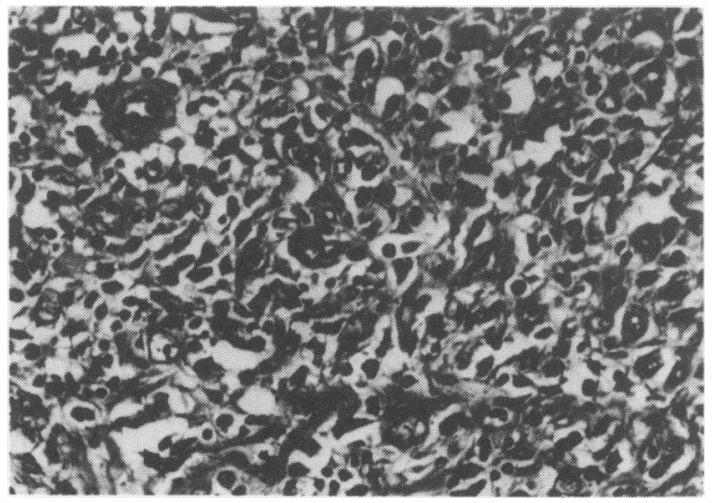

Figure 3 Microscopic section showing a markedly pleomorphic tumour composed of small histiocytic cells, large bizarre cells and multinucleated giant cells. A few spindle-shaped cells are also identified (haematoxylin \& eosin $\times 300$ ).
A final diagnosis of malignant fibrous histiocytoma of the posterior mediastinum was made. The fever and leucocytosis subsided after surgery. The patient was advised radiotherapy post-operatively. However, the patient declined it and was lost to follow-up.

\section{Discussion}

Malignant fibrous histiocytoma was first described in the mid-1960s. ${ }^{1,2}$ Since then, it has been recognized as the most common soft tissue sarcoma in adult life. It presents primarily in middle to late adult life. Out of 200 cases of this tumour reviewed, ${ }^{3}$ only 9 were younger than 20 years. It occurs most commonly in the extremities, thighs being the most common site. ${ }^{3,4}$ In two large series comprising 367 patients with this neoplasm, none had a mediastinal tumour. ${ }^{3,4}$

Malignant fibrous histiocytoma arising in the mediastinum has rarely been reported and to the best of our knowledge, only 8 such cases have been described to date. ${ }^{5-11}$ The previous youngest patient to have this tumour was 33 years of age. ${ }^{10}$ One case was asymptomatic and was detected on a routine $\mathrm{X}$-ray, while other patients had variable, nonspecific features in the form of cough, dyspnoea, back pain, ${ }^{5}$ superior vena cava obstruction ${ }^{9}$ or pleural effusion. ${ }^{6}$ The present case had a unique presentation with fever and leucocytosis which have not been described in such tumours located in the mediastinum. In a review of 200 cases of this tumour situated elsewhere, ${ }^{3}$ only 2 caseso had these features. The exact pathogenesis of these? features is unclear but these could be due to secretion of lymphokines by the tumour in some patients. Out of 8 mediastinal tumours, 7 were in the posterior mediastinum while one tumour was situated in the anterior mediastinum.?

The treatment of choice is surgical excision with or without radiotherapy. Both patients reported by Mills et $a l^{5}$ received post-operative radiotherapy. One of them was alive and doing well 56 months after surgery while the second patient was lost to follow-up. Two other cases were alive after 17 months $^{7}$ and 15 months ${ }^{11}$ after surgical removal alone. The remaining patients died during follow-up.

Malignant fibrous histiocytoma displays a pleomorphic histological picture because of which diagnosis is sometimes difficult with small biopsy specimens. In our case, the initial biopsy was interpreted as ganglioneuroma. In another reported case, the frozen section of the tumour was reported as ganglioneuroma. ${ }^{5}$

The case of malignant fibrous histiocytoma reported here is of interest because of its origin in the mediastinum, its occurrence at a young age and the presence of fever and leucocytosis which remitted after surgery. Despite its rarity, the possibility of a malignant fibrous histiocytoma should be considered in the differential diagnosis of a mediastinal tumour. 


\section{References}

1. Ozzelo, L., Stout, A.P. \& Murray, M.R. Cultural characteristics of malignant fibrous histiocytomas and fibrous xanthomas. Cancer 1963, 16: 331-334.

2. O'Brien, J.E. \& Stout, A.P. Malignant fibrous xanthomas. Cancer 1964, 17: 1445-1448.

3. Weiss, S.W. \& Enzinger, F.M. Malignant fibrous histiocytoma: An analysis of 200 cases. Cancer 1978, 41: 2250-2266.

4. Kearney, M.M., Soule, E.H. \& Irvins, J.C. Malignant fibrous histiocytoma. Cancer 1980, 45: 167-178.

5. Mills, S.A., Breyer, R.H., Johnston, F.R. et al. Malignant fibrous histiocytoma of the mediastinum and lung. A report of three cases. $J$ Thorac Cardiovasc Surg 1982, 84: $367-372$.

6. Chen, W., Chan, C.W. \& Mok, C.K. Malignant fibrous histiocytoma of the mediastinum. Cancer 1982, 50: 797-800.
7. Stark, P., Guthrie, A.M., Weitzner, S. \& Walker, W.E. Malignant fibrous histiocytoma of the mediastinum presenting as a retrosternal mass. Fortschr Rontgenstr 1983, 139: 327-329.

8. Besznyak, I., Svastits, E., Krasznai, G. \& Szentirmay, Z. Malignant fibrous histiocytoma of the mediastinum. Thorac Cardiovasc Surg 1985, 33: 106-108.

9. Simu, G. \& Macavei, I. Clinic and pathologic study of a case of inflammatory fibrous histiocytoma. Morphol Embryol 1986, 32: 201-204.

10. Venn, G.E., Gellister, J., DaCosta, P.E. \& Goldstraw, P. Malignant fibrous histiocytoma in thoracic surgical practice. J Thorac Cardiovasc Surg 1986, 91: 234-237.

11. Natsuaki, M., Yoshikawa, Y., Itoh, T., Minato, N. \& Yamada, H. Xanthogranulomatous malignant fibrous histiocytoma arising from posterior mediastinum. Thorax 1986, 41: 322-323. 